\title{
The Influence of Freeze-Thaw Cycles on Unconfined Compressive Strength of Lignin Fiber-Reinforced Loess
}

\author{
Zhongnan Gao ${ }^{1,2, \#}$, Xiumei Zhong ${ }^{1,2, \#}$, Qian Wang ${ }^{1,2, *}$, Yongqi Su ${ }^{3}$ and Jun Wang ${ }^{1,2}$ \\ ${ }^{1}$ Lanzhou Institute of Seismology, China Earthquake Administration, Lanzhou, 730000, China \\ ${ }^{2}$ Key Laboratory of Loess Earthquake Engineering, China Earthquake Administration \& Gansu Province, Lanzhou, 730000, China \\ ${ }^{3}$ Gansu Bureau of Coal Geology, Lanzhou, 730000, China \\ *Corresponding Author: Qian Wang. Email: wangq0930@126.com \\ \#These authors contributed to this work equally and should be regarded as co-first authors \\ Received: 06 May 2021 Accepted: 02 July 2021
}

\begin{abstract}
In the seasonal permafrost region with loess distribution, the influence of freeze-thaw cycles on the engineering performance of reinforced loess must be paid attention to. Many studies have shown that the use of fiber materials can improve the engineering performance of soil and its ability to resist freeze-thaw cycles. At the same time, as eco-environmental protection has become the focus, which has been paid more and more attention to, it has become a trend to find new environmentally friendly improved materials that can replace traditional chemical additives. The purpose of this paper uses new environmental-friendly improved materials to reinforce the engineering performance of loess, improve the ability of loess to resist freeze-thaw cycles, and reduce the negative impact on the ecological environment. To reinforce the engineering performance of loess and improve its ability to resist freeze-thaw cycles, lignin fiber is used as a reinforcing material. Through a series of laboratory tests, the unconfined compressive strength (UCS) of lignin fiber-reinforced loess under different freeze-thaw cycles was studied. The effects of lignin fiber content and freeze-thaw cycles on the strength and deformation modulus of loess were analyzed. Combined with the microstructure features, the change mechanism of lignin fiber-reinforced loess strength under freeze-thaw cycles was discussed. The results show that lignin fiber can improve the UCS of loess under freeze-thaw cycles, but the strengthening effect no longer increases with the increase of fiber content. When the fiber content is less than 1\%, the UCS growth rate of loess is the fastest under freeze-thaw cycles. And the UCS of loess with $1 \%$ fiber content is the most stable under freeze-thaw cycles. The freeze-thaw cycles increase the deformation modulus of loess with $1 \%$ fiber content, and its ability to resist deformation is obviously better than loess with $1.5 \%, 2 \%$ and $3 \%$ fiber content. The fiber content over $1 \%$ will weaken the strengthening effect of lignin fiber-reinforced loess, and the optimum fiber content of lignin fiber-reinforced loess under freeze-thaw cycles is $1 \%$.
\end{abstract}

\section{KEYWORDS}

Fiber-reinforced loess; freeze-thaw cycles; unconfined compressive strength; deformation modulus

\section{Introduction}

Loess is a kind of silt-dominated Quaternary sediment, which is mostly distributed in arid and semi-arid areas in the middle latitudes of the earth [1,2]. Natural loess has the characteristics of loose structure, large 
porosity, rich soluble salt and slightly coherent, and often shows the metastable microstructure [3-6]. Since this special structure features, loess may collapse after wetting $[7,8]$. In practical engineering, loess is treated by compaction and improvement to make its engineering performance meet the construction requirements, so that it, a cheap local material, can be used as fill and foundation soil for infrastructure in loess areas $[9,10]$. However, in seasonal permafrost regions with loess distribution, the influence of freeze-thaw cycles caused by climate change on the engineering performance of loess must be paid attention to. When loess stays in the process of repeated freeze-thaw cycles, the volume change caused by the mutual transformation of water between liquid and solid will lead to changes in the structure and physical and mechanical properties of loess. The original equilibrium state of loess will be broken and transform into a new equilibrium state. In serious cases, it may even affect the long-term safe and stable operation of the infrastructure in the loess area. Engineering problems such as settlement, deformation and cracks in highway and railway facilities may happen [9,11-13]. Therefore, while studying the application of improved materials to reinforce the engineering performance of loess, the influence of freeze-thaw cycles on the improved loess should also be considered [14-16].

In recent years, there have been continuous reports on the mechanical properties of reinforced soil by new improved materials, especially fiber-reinforced soil under freeze-thaw cycles. Zaimoglu [17] found that under the 12 freeze-thaw cycles, the unconfined compressive strength of the fine-grained reinforced soil with $0.75 \%$ polypropylene fiber content increased from $311 \mathrm{kPa}$ to $905 \mathrm{kPa}$ compared with the unreinforced soil. Kravchenko et al. [18] found that after 15 freeze-thaw cycles, the shear strength of $0.75 \%$ polypropylene fiber-reinforced soil and $0.75 \%$ basalt fiber-reinforced soil increased by $71 \%$ and $27.1 \%$, respectively, compared with unreinforced soil. Orakoglu et al. [18] found that after being reinforced by glass fiber and basalt fiber, the loss ratio of shear strength and clay cohesion under freezethaw cycles decreased in varying degrees. Yarbasi [19] found that the unconfined compressive strength of clayey soil mixed $1.5 \%$ human hair fiber was $49 \%$ higher than that of unreinforced soil after freeze-thaw cycles. Liu et al. [20] found that the unconfined compressive strength of clay with $0 \%, 0.2 \%$ and $0.4 \%$ cotton fiber after 20 freeze-thaw cycles was $186 \mathrm{kPa}, 236 \mathrm{kPa}$ and $278 \mathrm{kPa}$, respectively, which decreased by $37.58 \% 25.55 \%$ and $23.20 \%$ respectively compared with that without freeze-thaw cycles. Liu et al. [21] found that under the one freeze-thaw cycle, the tensile strength of $0.25 \%$ polypropylene fiberreinforced silty clay increased from $47.66 \mathrm{kPa}$ to $120.48 \mathrm{kPa}$, and the strength increased by $152.8 \%$. Güllü et al. [22] found that jute fiber can improve the compressive strength of silt under freeze-thaw cycles, and can improve the energy-absorption capacity and ductility. Eskisar et al. [23] found that the addition of polypropylene fiber can enhance the compressive strength of soil, reduce the weakening effect of freeze-thaw cycles on soil compressive strength, and improve the freeze-thaw durability of soil. These previous studies show that fiber materials can effectively improve the unconfined compressive strength, shear strength, tensile strength and ductility of soil under the condition of freeze-thaw cycles. The interface interaction between fiber and soil particles can bear part of the tensile stress caused by soil expansion in the process of the freeze-thaw cycle, which is helpful to reduce the weakening effect of freeze-thaw cycles on soil strength [13,24,25]. Moreover, the production of traditional chemical additives will lead to the consumption of fossil energy and non-renewable clay minerals and greenhouse gas emissions [26]. Their use may also increase the $\mathrm{pH}$ value of the soil, which will lead to the reduction of vegetation, the pollution of groundwater and the corrosion of building structures [27]. All these problems hurt the ecological environment. As more and more attention has been paid to environmental protection, the negative effects of traditional chemical additives on the environment have been paid more and more attention. Because the process of fiber materials to enhance soil strength is usually a physical process, environmental protection fiber materials have obvious advantages in overcoming the shortcomings of traditional chemical additives [28,29]. Therefore, it is feasible and urgent to find a suitable environmental protection material among many fiber materials to reinforce the engineering performance of soil and improve the ability of soil to resist freeze-thaw cycles. 
Lignin fiber has huge storage, which not only has the advantages of fiber materials, but also has the characteristics of strong renewability, low cost and low environmental impact [30]. It is a potential, environment-friendly and economical soil improvement material. At present, a variety of lignin have been used as additives to improve soil properties in many studies, and some results have been achieved. Such as, Alazigha et al. [31] studied the mechanism of lignin sulfonate modified remolded expansive soil. Zhang et al. [32,33] evaluated the mechanical properties of lignin stabilized silt and carried out a field experimental study on the feasibility of lignin as a modified material for highway roadbed. Kong et al. [34] studied the compactness, compressive strength and water stability of lignin stabilized silt. Wang et al. [35] studied the dynamic characteristics of lignin-modified loess. Liu et al. [36] studied the compressive strength and mechanism of lignin modified clay. These studies are mainly focused on clay and silt, but less on loess, which were mostly carried out at room temperature and less under the condition of freeze-thaw cycles. Especially the study of lignin fiber enhancing the strength of loess under freeze-thaw cycle conditions has not yet been seen.

The study analyzes the effect of freeze-thaw cycles on the strength of lignin fiber-reinforced loess through a series of unconfined compressive strength tests, and summarize the law of different lignin fiber content to enhance the strength of loess under the condition of freeze-thaw cycles. And combined with the microstructure features, the reason for the difference of this intensity change law is discussed. Finally, the optimal lignin fiber content to improve the freeze-thaw resistance of loess is given. The results can fill the gap in the study of the effect of freeze-thaw cycles on the strength of lignin fiberreinforced loess, and provide a reference for the follow-up study of lignin fiber-reinforced loess under the condition of freeze-thaw cycles. It is also helpful to the application of environmental protection material lignin fiber in the loess area.

\section{Materials and Methods}

\subsection{Test Materials}

The loess used in the tests is typical loess in northwest China, which comes from Xiji County, Ningxia Hui Autonomous Region. The loess texture is uniform and the color is yellowish (Fig. 1a). Before specimen preparation, the specific gravity test, Atterberg limit test, compaction test, particle distribution test, triaxial shear test and consolidation test of loess were carried out according to Specification of soil test: GB/ T50123-2019 [37]. The basic properties of loess are listed in Table 1, and the grading curve of loess is shown in Fig. 2. The lignin fiber used in the test comes from Hebei Province, China, its appearance is white powder with many small particles (Fig. 1b). Its engineering performance is shown in Table 2.

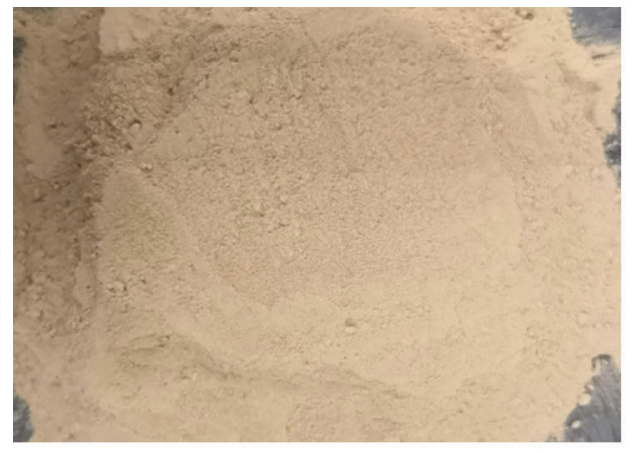

(a)

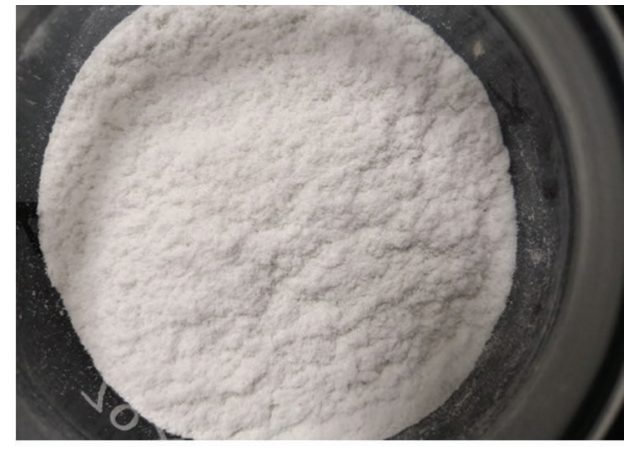

(b)

Figure 1: Materials used in the study: (a) loess; (b) lignin fiber 
Table 1: Physical properties of loess

\begin{tabular}{ll}
\hline Property & Value \\
\hline Specific gravity & 2.72 \\
Liquid limit $(\%)$ & 24.0 \\
Plastic limit (\%) & 14.5 \\
Plasticity index & 9.5 \\
Maximum dry density $\left(\mathrm{g} / \mathrm{cm}^{3}\right)$ & 1.79 \\
Optimum moisture content $(\%)$ & 14.5 \\
Cohesion $(\mathrm{kPa})$ & 35.4 \\
frictional angle $\left({ }^{\circ}\right)$ & 30.3 \\
modulus of compression $(\mathrm{MPa})$ & 14.6 \\
\hline
\end{tabular}

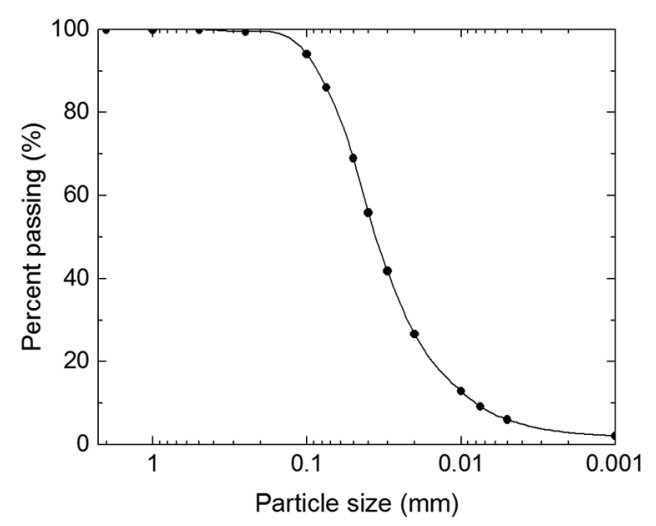

Figure 2: Loess particle gradation curve

Table 2: Engineering properties of lignin fiber

\begin{tabular}{ll}
\hline Property & Value \\
\hline Length $(\mathrm{mm})$ & $<1$ \\
Average diameter $(\mu \mathrm{m})$ & 40 \\
Bulk density $(\mathrm{g} / \mathrm{L})$ & 27 \\
Moisture content $(\%)$ & $<5$ \\
Ash content $(\%)$ & 18 \\
Heat resisting ability $\left({ }^{\circ} \mathrm{C}\right)$ & 230 \\
$\mathrm{pH}$ & 7.0 \\
\hline
\end{tabular}

\subsection{Test Method}

\subsubsection{Specimen Preparation}

The lignin fiber content of the specimen used in the study was $\mathrm{m}=0 \%, 1 \%, 1.5 \%, 2 \%$ and $3 \%$, respectively. The content is the ratio mass of fiber to dry loess [16,20]. The specimens were prepared according to Specification of soil test: GB/T50123-2019 [37]. The specimen preparation process is: First, the sieve is used to remove particles larger than $2 \mathrm{~mm}$ in natural air-dried loess. Second, put the dried 
loess into a bowl and mix it with a certain amount of lignin fiber. In order to ensure the uniform mixing of fiber and loess, the step-by-step mixing method is adopted in the mixing process. For each mixing, first sprinkle a small layer of fiber on the dry loess in the basin, then stir clockwise for at least two minutes. After mixing evenly, repeat the next time until all the fibers are added to the loess. Third, pure water is added to the dry mixed loess until the moisture content of the mixed soil reaches the optimal moisture content $(14.5 \%)$. In the process of adding pure water, stir and rub are carried out at the same time to ensure that the water is evenly mixed. After the fiber, loess and water are mixed evenly, the mixture is placed in a plastic container for $24 \mathrm{~h}$ to ensure that the water in the mixture spreads evenly. Finally, the mixture is loaded into a cylindrical mold with an inner diameter of $39.1 \mathrm{~mm}$, and a cylindrical specimen with a height of $80 \mathrm{~mm}$ and a diameter of $39.1 \mathrm{~mm}$ is compacted by double-end static pressure method (Fig. 3). In order to better compare and analyze the results, the dry density of all specimens is calculated according to the maximum $1.79 \mathrm{~g} / \mathrm{cm}^{3}$ and the compaction coefficient $94 \%$ [38,39]. After the compaction is completed, carefully remove the specimens from the mold to prevent the reinforced loess specimens from being damaged by collision. As preparing numerous specimens take a lot of time, the specimens need to be placed in the curing device for a period. In order to ensure that the specimens go through the same process and avoid the loss of moisture during curing, all the specimens were cured for 28 days after they were wrapped with three-layer plastic film. The curing temperature was $20 \pm 2^{\circ} \mathrm{C}$ and the relative humidity was $95 \%$. The curing conditions referred to the conditions used by Wang et al. [40].

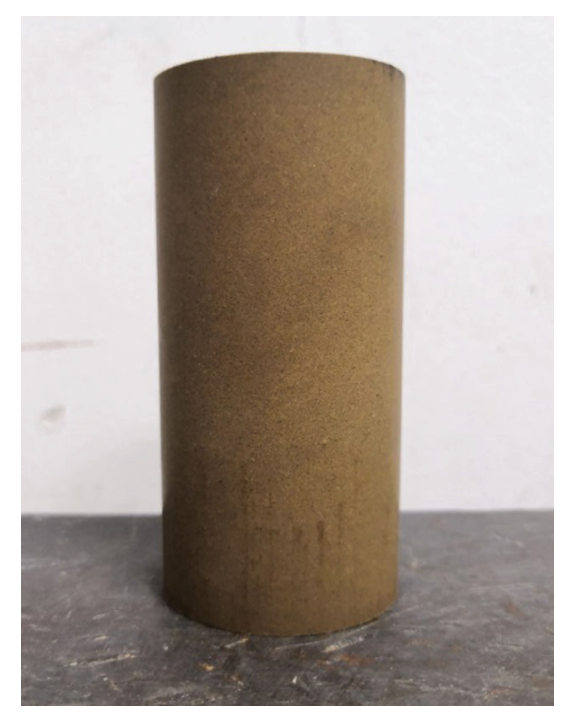

Figure 3: Lignin fiber-reinforced loess specimen

\subsubsection{Freeze-Thaw Cycles}

After curing, the specimens were subjected to freeze-thaw cycles in batches in a high and low temperature test instrument (Fig. 4). The freeze-thaw cycles of the specimens were 0, 1, 5, 10, 15 and 20, respectively. The temperature and time conditions of a freeze-thaw cycle are: freeze at $-20^{\circ} \mathrm{C}$ for $12 \mathrm{~h}$, and then thaw at $20^{\circ} \mathrm{C}$ for $12 \mathrm{~h}$ (Fig. 5). This condition has been used in some previous studies [41]. The freeze-thaw cycle times and conditions are automatically controlled by the test chamber. Table 3 shows the freeze-thaw cycle scheme of the specimen before the test. 


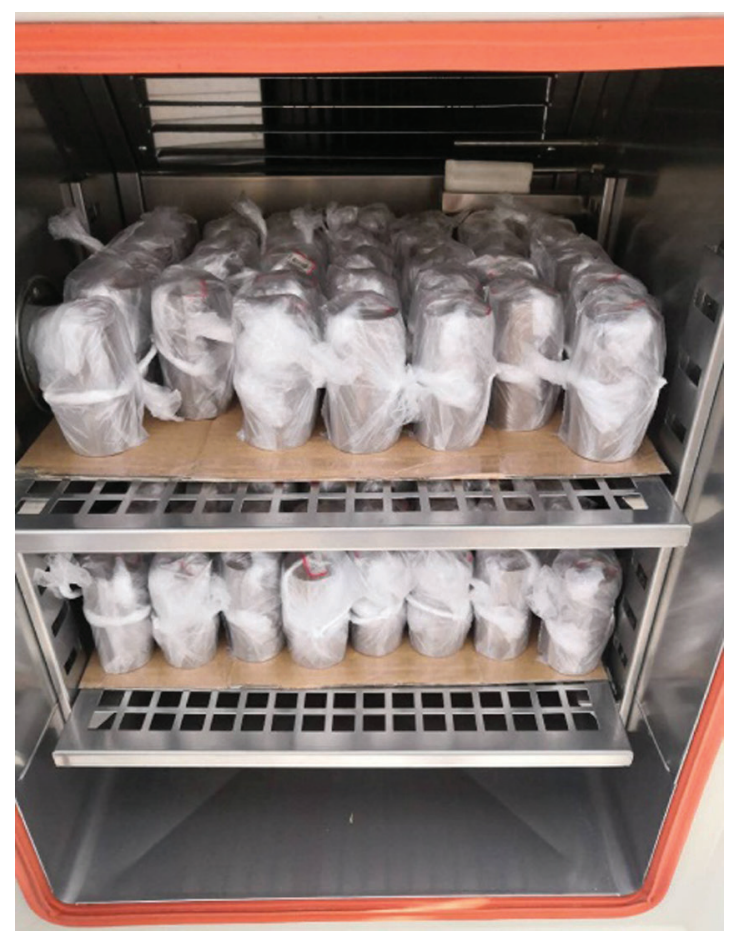

Figure 4: Specimen placed in high and low temperature test instrument

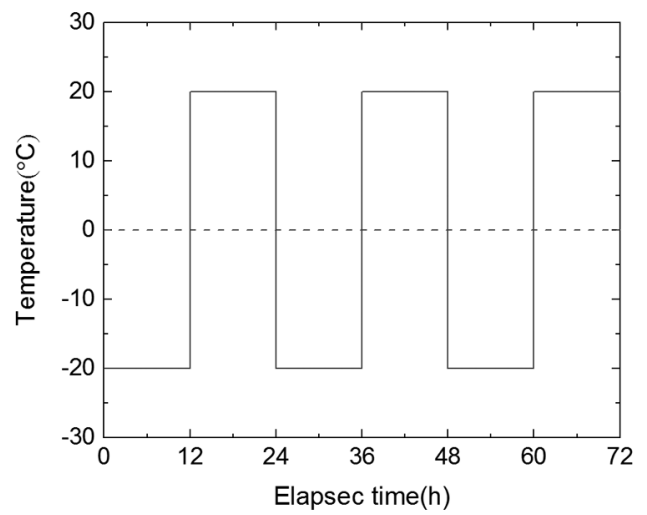

Figure 5: Specimen temperature $v s$. time during freezing and thawing

Table 3: Freeze-thaw cycle scheme of specimen

\begin{tabular}{lcccccc}
\hline $\begin{array}{l}\text { Fiber content } \\
(\%)\end{array}$ & \multicolumn{2}{l}{$\begin{array}{l}\text { Number of freeze-thaw } \\
\text { cycles }\end{array}$} & \multicolumn{2}{c}{ Temperature $\left({ }^{\circ} \mathrm{C}\right)$} & & \multicolumn{2}{c}{ Time (hours) } \\
\cline { 3 - 4 } \cline { 5 - 6 } & & freeze & thaw & & Freeze & thaw \\
\hline 0 & $0,1,5,10,15$ & -20 & 20 & & 12 & 12 \\
1 & & & & & & \\
1.5 & & & & & & \\
2 & & & & & & \\
3 & & & & & & \\
\hline
\end{tabular}




\subsubsection{UCS Tests}

The YYW- 2 strain controlled unconfined compression testing machine was used in the UCS test, and the loading rate was $2.4 \mathrm{~mm} / \mathrm{min}$ (Fig. 6). The test is carried out under the procedures in the "Specification of soil test" (GB/T50123-2019) [37]. When the stress of the specimen reaches its peak, continue loading to increase the strain by another $3 \%$ and stop the test.

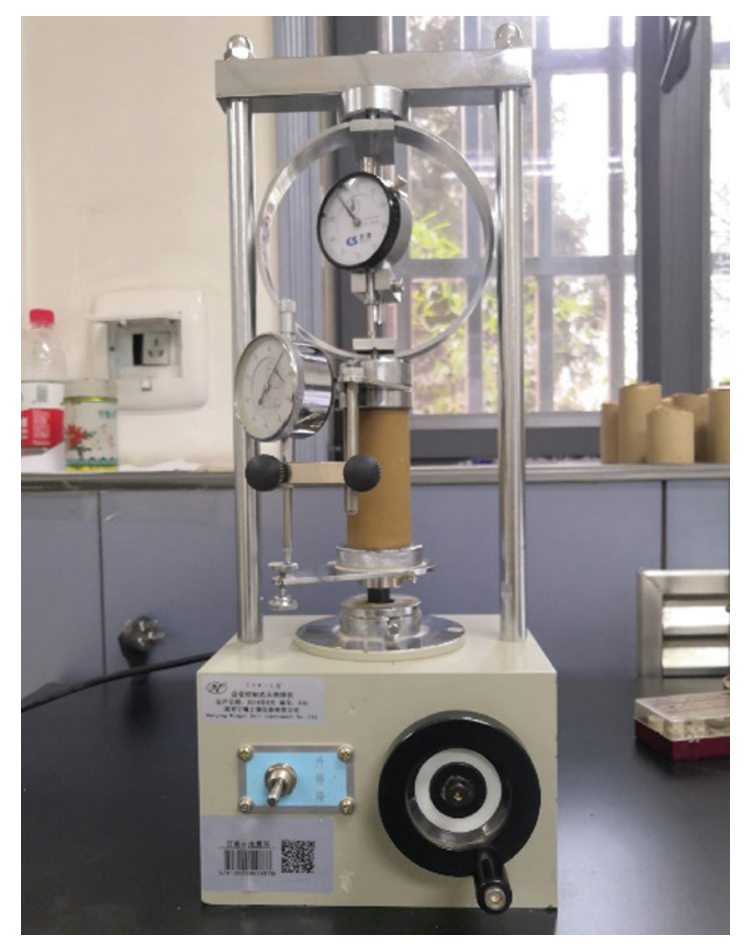

Figure 6: Unconfined compression testing machine with specimen installed

\subsubsection{Scanning Electron Microscopy (SEM) Tests}

Representative microstructure pictures of lignin fiber-reinforced loess were got by KYKY-2800B scanning electron microscope. The specimen of electron microscope needs to be prepared before scanning. The preparation process is: First, the vacuum freeze drying equipment was used to dry the loess specimen. Then the suitable part was selected in the loess specimen and the flake electron microscope specimen was made through manual grinding. Finally, the flake specimen was glued to the sample bracket with conductive adhesive, and the gold was sprayed by an ion sputtering instrument. The magnification of the microstructure image of the specimen got by scanning was 400 times, which is helpful to analyze the reason for the change of macroscopic mechanical properties of reinforced loess caused by freeze-thaw cycles.

\section{Results}

According to the unconfined compressive strength test data, the stress-strain curves of different fiber content specimens under different freeze-thaw cycles are shown in Fig. 7.

As shown in Fig. 7, there are obvious peaks in the stress-strain curves of the specimens before and after freeze-thaw cycles. All the specimens with different fiber content showed strain softening behavior. The stress-strain curve of the unreinforced specimen (i.e., $\mathrm{m}=0 \%$ ) is little affected by the freeze-thaw cycles, and the peak stress and the corresponding axial failure strain only slightly decrease after 1 freeze-thaw 
cycle. And there is no change under the subsequent freeze-thaw cycle. This is consistent with the results of Li et al. [11]. The change rule of stress-strain curve of $1 \%$ fiber content specimen is basically the same as that of the unreinforced specimen. After 1 and 5 freeze-thaw cycles, the peak stress and sharpness of the stress-strain curve of reinforced loess with $1.5 \%, 2 \%$, and $3 \%$ fiber content are all decreased, while the axial failure strain increased slightly. After 10 freeze-thaw cycles, the stress-strain curves of reinforced loess with $1.5 \%, 2 \%$, and $3 \%$ fiber content no longer changed significantly. The freeze-thaw cycle reduced the UCS of fiber-reinforced loess.
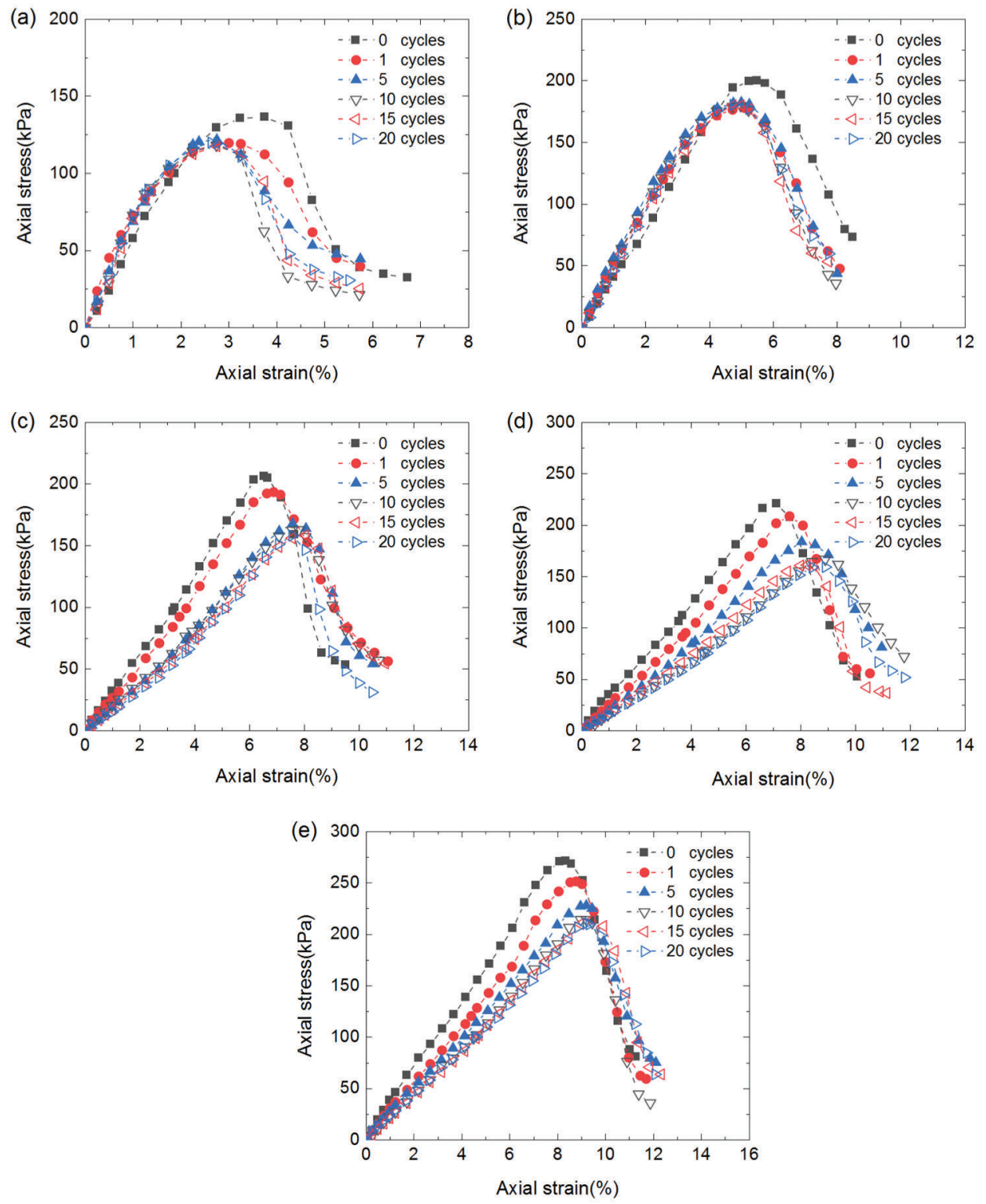

Figure 7: Stress-strain curves of lignin fiber-reinforced loess with different fiber content: (a) $0 \%$, (b) $1 \%$, (c) $1.5 \%$, (d) $2 \%$, and (e) $3 \%$

The influence of fiber on the stress-strain relationship of loess under freeze-thaw cycles was further explained. The peak stress and final stress (i.e., the stress at the end of the test) of the specimens after 10, 15 and 20 freeze-thaw cycles were statistically analyzed. The results are shown in Table 4. After the 
stress-strain relationship of the specimens with different fiber content is stable (i.e., after 10 freeze-thaw cycles), the final stresses of $0 \%, 1 \%, 1.5 \%, 2 \%$, and $3 \%$ fiber content specimens are reduced by $80 \%$, $73 \%, 71 \%, 68 \%$, and $75 \%$, respectively, compared with their respective peak stresses. After fiber reinforcement, the peak stress reduction ratio of loess decreased. Fiber could reduce the softening degree of frozen-thawed loess under unconfined conditions, which is the same as the results reported by Liu et al. [20].

Table 4: Statistical evaluation of peak stress and final stress of specimen

\begin{tabular}{llllllll}
\hline \multirow{2}{*}{$\begin{array}{l}\text { Fiber content } \\
(\mathrm{m})(\%)\end{array}$} & \multicolumn{3}{c}{ Peak stress } & & \multicolumn{3}{c}{ Final stress } \\
\cline { 2 - 4 } & $\begin{array}{l}\text { Geometric } \\
\text { mean }(\mathrm{kPa})\end{array}$ & $\begin{array}{l}\text { Standard } \\
\text { deviation }(\%)\end{array}$ & $\begin{array}{l}\text { Standard } \\
\text { error }(\%)\end{array}$ & & $\begin{array}{l}\text { Geometric } \\
\text { mean }(\mathrm{kPa})\end{array}$ & $\begin{array}{l}\text { Standard } \\
\text { deviation }(\%)\end{array}$ & $\begin{array}{l}\text { Standard } \\
\text { error }(\%)\end{array}$ \\
\hline 0 & 119 & 1.15 & 0.67 & 24 & 2.65 & 1.53 \\
1 & 180 & 0.58 & 0.33 & & 49 & 12.34 & 7.13 \\
1.5 & 160 & 2.89 & 1.67 & & 46 & 14.49 & 8.35 \\
2 & 163 & 4.73 & 2.73 & & 52 & 17.56 & 10.14 \\
3 & 213 & 1.73 & 1.00 & 53 & 16.17 & 9.3 \\
\hline
\end{tabular}

\section{$3.1 \mathrm{UCS}$}

To more intuitively analyze the influence of freeze-thaw cycles and fiber content on the unconfined compressive strength of reinforced loess, the dimensionless quantitative treatment was carried out. The UCS $\left(S_{m} / S_{m=0}\right)$ ratio was defined as the ratio of the UCS $\left(S_{m}\right)$ of the given fiber content specimen to the UCS $\left(S_{m=0}\right)$ of the unreinforced specimen in the same freeze-thaw cycle. It can reflect the effect of fiber content on the strengthening effect of loess under the same freeze-thaw cycle. The variation of UCS ratio with fiber content is shown in Fig. 8.

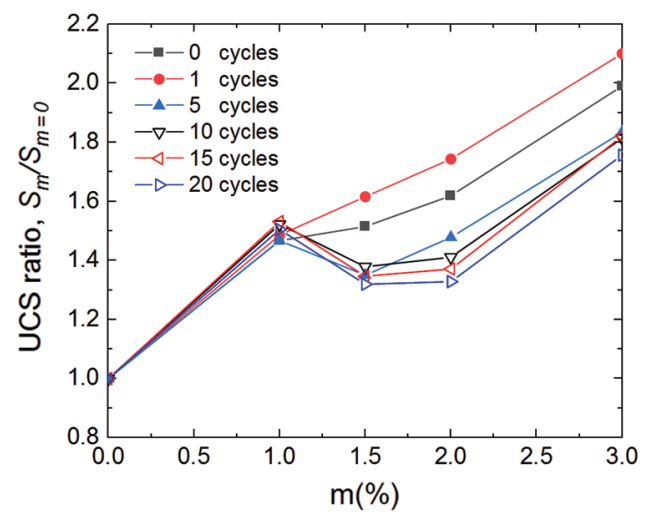

Figure 8: Variation in the UCS ratio with fiber content

As shown in Fig. 8, the change law of UCS ratio is different under different times of freeze-thaw cycles. The UCS ratio of the specimens without freeze-thaw cycles increases with the increase of fiber content, but the increase slows down when the fiber content increases from $1 \%$ to $2 \%$. After 1 freeze-thaw cycle, the UCS ratio of $1 \%$ fiber content specimen does not change obviously. The UCS ratios of $1.5 \%, 2 \%$, and $3 \%$ fiber content specimens are larger than that of the specimens without freeze-thaw cycles. The relationship between UCS ratio and fiber content is still positively correlated. 
After 5 freeze-thaw cycles, the UCS ratio of $1 \%$ fiber content specimen still does not change significantly. The UCS ratios of $1.5 \%, 2 \%$, and $3 \%$ fiber content specimens decrease significantly, and they are again smaller than the specimens without freeze-thaw cycles with the same fiber content. The UCS ratio of $1.5 \%$ fiber content specimen has been less than $1 \%$ fiber content specimen. At this time, with the increase of fiber content, the strengthening effect of fiber on loess begins to show the law of first strengthening and then weakening, and then second strengthening.

After 10 freeze-thaw cycles, the UCS ratios of $1 \%$ and $3 \%$ fiber content specimen remain basically stable. Like $1.5 \%$ fiber content specimens, the UCS ratio of $2 \%$ fiber content specimens begins to be less than $1 \%$ fiber content specimens. The change rule of UCS ratio is basically the same as that after 5 freeze-thaw cycles. The UCS ratios of the specimens after 15 and 20 freeze-thaw cycles are not significantly different from those after 10 freeze-thaw cycles, and the change rules of UCS ratio do not change. After 10, 15, and 20 freeze-thaw cycles, the UCS ratios of $1 \%, 1.5 \%, 2 \%$, and $3 \%$ fiber content specimens ranges from 1.51 to $1.53,1.32$ to $1.38,1.33$ to 1.41 , and 1.76 to 1.81 , respectively. Although the UCS ratio of fiber-reinforced loess no longer increases with the increase of fiber content, the UCS ratios of $1 \%, 1.5 \%, 2 \%$, and $3 \%$ fiber content specimens are still all greater than 1 . This means that although the fiber can enhance the strength of loess under the condition of freeze-thaw cycles. However, when the strength of fiber-reinforced loess begins to stabilize under the action of freeze-thaw cycles, there is no positive correlation between reinforcement effect and fiber content.

Therefore, in order to further illustrate the strengthening effect of fiber content on loess UCS under the influence of freeze-thaw cycles, the change rate of UCS ratio of each fiber content range after different freezethaw cycles is listed in Table 5. The change rate of UCS ratio is the inverse ratio of the difference of fiber content and the difference of the corresponding UCS ratio.

Table 5: The change rate of UCS ratio in each fiber content range

\begin{tabular}{lllllll}
\hline $\begin{array}{l}\text { Fiber content } \\
\text { range (\%) }\end{array}$ & \multicolumn{6}{c}{ Rate of change of different freeze-thaw cycles (\%) } \\
\cline { 2 - 7 } & 0 & 1 & 5 & 10 & 15 & 20 \\
\hline $0 \sim 1$ & 47 & 49 & 47 & 52 & 53 & 51 \\
$1 \sim 1.5$ & 10 & 26 & -23 & -30 & -37 & -37 \\
$1.5 \sim 2$ & 21 & 26 & 26 & 7 & 5 & 2 \\
$2 \sim 3$ & 37 & 36 & 36 & 40 & 45 & 43 \\
\hline
\end{tabular}

As we can see from Table 5, the strengthening rate of fiber to UCS of loess is the fastest when the fiber content increases from $0 \%$ to $1 \%$ under different freeze-thaw cycles. When the fiber content increases from $1 \%$ to $2 \%$, the strengthening rate of the fiber to UCS of loess is lower than that when the fiber content increases from $0 \%$ to $1 \%$ and from $2 \%$ to $3 \%$. After 10 freeze-thaw cycles, the strengthening rate of fiber on loess strength remains basically stable when the fiber content increases from $0 \%$ to $1 \%$ and from $2 \%$ to $3 \%$. When the fiber content increases from $1 \%$ to $2 \%$, the strengthening rate of fiber on UCS of loess begins to decrease. When the fiber content increases from $1 \%$ to $1.5 \%$, the strengthening rate becomes negative. This may be because of the different degrees of response of the specimens with different fiber content to the freeze-thaw cycles, and the specific causes will be discussed in the later part of the paper.

Based on the above analysis, it can be found that the freeze-thaw cycle will weaken the strengthening effect of fiber on UCS of loess, but the weakening extent of loess with different fiber content is different. Therefore, it is necessary to analyze the change of UCS loss rate $\left(\Delta S_{n} / S_{n=0}\right)$ of the same fiber content specimen during the freeze-thaw cycle. Fig. 9 shows the effect of freeze-thaw cycles on the specimens 
with different fiber content. The UCS loss rate is determined by the ratio of the UCS change of the specimen after freeze-thaw cycles to the UCS of the specimen without freeze-thaw cycles with the same fiber content. The change of UCS $\left(\Delta S_{n}\right)$ is the difference between UCS $\left(S_{n=0}\right)$ without freeze-thaw cycles and UCS $\left(S_{n}\right)$ after a given number (n) of freeze-thaw cycles.

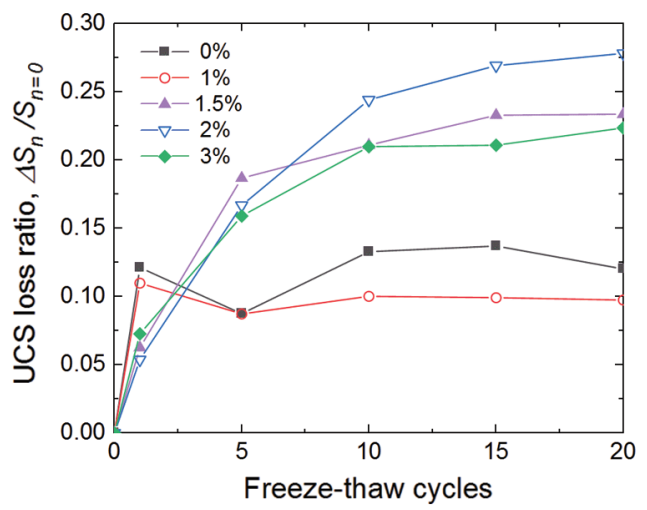

Figure 9: Variation in the UCS loss ratio with freeze-thaw cycles

According to Fig. 9, the UCS loss rate of the specimens with different fiber content increases at first and then tends to be stable, but the number of freeze-thaw cycles that begin to stabilize is different. The UCS loss rates of $0 \%$ and $1 \%$ fiber content specimens increase at first, and then suddenly tend to stabilize. After 1 freeze-thaw cycle, the UCS loss rates of $0 \%, 1 \%, 1.5 \%, 2 \%$, and $3 \%$ fiber content specimens are 0.12 , $0.11,0.06,0.05$, and 0.07 , respectively. The UCS loss rates of $0 \%$ and $1 \%$ fiber content specimens are all significantly higher than that of $1.5 \%, 2 \%$, and $3 \%$ fiber content specimens. The influence of 1 freezethaw cycle on $0 \%$ and $1 \%$ fiber-reinforced loess is greater than $1.5 \%, 2 \%$ and, $3 \%$ fiber-reinforced loess.

However, after 5 freeze-thaw cycles, the UCS loss rates of $0 \%, 1 \%, 1.5 \%, 2 \%$, and $3 \%$ fiber content specimens are $0.09,0.09,0.19,0.17$, and 0.16 , respectively. The UCS loss rates of $0 \%$ and $1 \%$ fiber content specimens are less than 1.5\%, 2\%, and 3\% fiber content specimens. After 5 freeze-thaw cycles, $1.5 \%, 2 \%$, and $3 \%$ fiber-reinforced loess are more affected than $0 \%$ and $1 \%$ fiber-reinforced loess. The UCS loss rates of $0 \%$ and $1 \%$ fiber content specimens after 10, 15, and 20 freeze-thaw cycles are between 0.12 and $0.14,0.10$ and 0.11 , respectively, which change little compared with those of 1 and 5 freeze-thaw cycles. It can be considered that the response of $0 \%$ and $1 \%$ fiber-reinforced loess to freeze-thaw cycles begins to decrease after 1 freeze-thaw cycle, and their strength changes begin to stabilize. And the UCS loss rate of $1 \%$ fiber-reinforced loess is slightly lower than that of unreinforced loess under the condition of freeze-thaw cycles.

The UCS loss rates of $1.5 \%, 2 \%$, and $3 \%$ fiber content specimens have little difference after 1 freezethaw cycle. After 5 freeze-thaw cycles, the UCS loss rates of $1.5 \%, 2 \%$ and $3 \%$ fiber content specimens are $0.19,0.17$, and 0.16 , respectively, and the UCS loss rates of $1.5 \%$ fiber content specimens are the highest among the three. After 10 freeze-thaw cycles, the UCS loss rates of $1.5 \%, 2 \%$, and $3 \%$ fiber content specimens are $0.21,0.24$, and 0.21 , respectively. The UCS loss rate of $2 \%$ fiber content specimen is higher than that of $1.5 \%$ fiber content specimen, which is the highest among the three. After 5, 10, 15, and 20 freeze-thaw cycles, the UCS loss rate of the specimens with 3\% fiber is the lowest among the three. The UCS loss rates of $1.5 \%, 2 \%$, and $3 \%$ fiber content specimens after 10, 15, and 20 freeze-thaw cycles are between 0.21 and $0.23,0.24$ and $0.28,0.21$ and 0.22 , respectively. It can be considered that $1.5 \%, 2 \%$, and $3 \%$ fiber-reinforced loess begin to enter a stable stage after 10 freeze-thaw cycles, and $2 \%$ fiber-reinforced loess after stabilization is most affected by the freeze-thaw cycles. By comparing the 
UCS loss rate of all fiber content specimens, it can be found that $1 \%$ fiber-reinforced loess has the best stability under freeze-thaw cycles, the strongest ability to resist freeze-thaw cycles, and $2 \%$ fiberreinforced loess has the worst ability to resist freeze-thaw cycles.

\subsection{Modulus of Deformation $E_{50}$}

$E_{50}$ was used as the evaluation index to evaluate the deformation properties of lignin fiber-reinforced loess. $E_{50}$ is the secant slope from the origin to the point of $50 \%$ axial failure strain. The calculation formula is as follows [42]:

$E_{50}=\frac{2 \sigma_{1 / 2}}{\varepsilon_{f}}$

where: $\sigma_{1 / 2}$ is the stress value when the axial failure strain reaches half; $\varepsilon_{f}$ is the axial failure strain corresponding to the peak stress. $E_{50}$ is also quantified dimensionless to eliminate the influence of different factors on deformation modulus. The modulus ratio $\left(E_{50 m} / E_{50 m=0}\right)$ of specimens with the same freeze-thaw cycles is defined as the ratio of the deformation modulus $\left(E_{50 \mathrm{~m}}\right)$ of reinforced loess with given fiber content $(\mathrm{m})$ to deformation modulus $\left(E_{50 m=0}\right)$ of unreinforced loess in the same freeze-thaw cycle, which can reflect the effect of fiber content on the deformation modulus of loess under the same freeze-thaw cycle. The variation of the modulus ratio with fiber content of the specimen with the same number of freeze-thaw cycles is shown in Fig. 10.

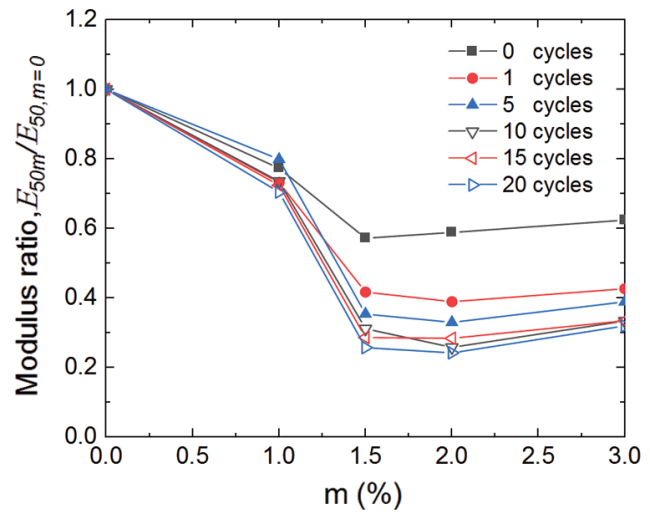

Figure 10: Variation of modulus ratio with fiber content of specimens with the same freeze-thaw cycles

As shown in Fig. 10, the modulus ratio of the specimens with different freeze-thaw cycles decreases at first and then tends to be stable with the increase in fiber content. For the specimens after different freezethaw cycles, the modulus ratio decreases the fastest when the fiber content increases from $1 \%$ to $1.5 \%$, and the change of fiber content has the most significant effect on the modulus ratio. When the fiber content increases from $1.5 \%$ to $3 \%$, the modulus ratio of the specimen is basically maintained at a stable level. This shows that the increase in fiber content weakens the ability of fiber-reinforced loess to resist deformation, but this weakening effect is limited. When the fiber content is over $1.5 \%$, the deformation characteristics of fiber-reinforced loess no longer change obviously.

The effects of freeze-thaw cycles on specimens with different fiber content are different. Fig. 11 shows that the modulus ratio of specimens with the same fiber content varies with freeze-thaw cycles. The modulus ratio $\left(E_{50 n} / E_{50 n}=0\right)$ of the specimen with the same fiber content is the deformation modulus $\left(E_{50 n}\right)$ of the specimen with the same fiber content after a given number of freeze-thaw cycles divided by the deformation modulus $\left(E_{50 n=0}\right)$ of the specimen without freeze-thaw cycles. 


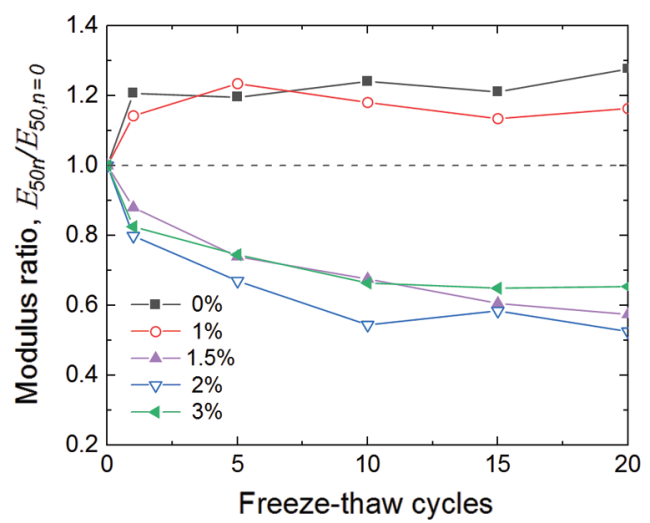

Figure 11: Variation of modulus ratio of specimens with the same fiber content with freeze-thaw cycles

According to Fig. 11, the variation trend of modulus ratio of specimens with different fiber content with the number of freeze-thaw cycles can be divided into two categories. The modulus ratio of $0 \%$ and $1 \%$ fiber content specimens increases at first and then stable. The modulus ratios of $0 \%$ and $1 \%$ fiber content specimens are in the range of 1.21 to 1.28 and 1.13 to 1.23 , respectively, after $1,5,10,15$, and 20 freezethaw cycles. The effect of freeze-thaw cycles increases the deformation modulus of unreinforced loess and $1 \%$ fiber loess, and enhances the ability of both to resist deformation.

The modulus ratio of $1.5 \%, 2 \%$, and $3 \%$ fiber content specimens decrease at first and then tend to be stable. The modulus ratio of $1.5 \%, 2 \%$, and $3 \%$ fiber content specimens decrease most significantly after 1 freeze-thaw cycle, and remain stable after 10 freeze-thaw cycles. The modulus ratios of $1.5 \%, 2 \%$, and $3 \%$ fiber content specimens after 10, 15, and 20 freeze-thaw cycles are in the range from 0.57 to 0.67 , 0.52 to 0.58 , and 0.65 to 0.66 , respectively. The freeze-thaw cycle greatly reduces the deformation modulus of $1.5 \%, 2 \%$, and $3 \%$ fiber-reinforced loess, weakening their ability to resist deformation.

\section{Discussion}

Based on the results of UCS test, it can be found that the relationship between macroscopic mechanical properties and fiber content was different between the specimens without freeze-thaw cycles and those after freeze-thaw cycles. In order to analyze the reasons for this difference, the representative microstructure pictures of fiber-reinforced loess after 0 and 10 freeze-thaw cycles were compared and analyzed. The results of the analysis are shown in Fig. 12.

Without freeze-thaw cycles, the unreinforced loess $(\mathrm{m}=0 \%)$ had obvious overhead pores, the contact between soil particles was mainly point contact, the surface of particles had less cohesive substances, and the pore filling is insufficient. With the increase of fiber content, the pores of the reinforced loess become smaller, the pore connectivity became worse, the pore distribution became more uniform, the cohesive polymer on the particle surface increased, and the soil became denser. This phenomenon is related to the filling of loess pores by tiny particles (detritus) in lignin fiber. The strength of reinforced loess without freeze-thaw cycles increases with the increase of fiber content, which should be closely related to the filling effect and the interaction between fiber and soil interface [43].

By comparing the microstructure characteristics of reinforced loess before and after freeze-thaw cycles, it could be found that the pores in $0 \%, 1 \%$, and $3 \%$ fiber-reinforced loess all slightly increase after 10 freezethaw cycles. This phenomenon is obviously caused by the change of water volume in the soil during freezethaw cycles. Except for water, the strength of loess is obviously related to fiber content and soil properties. Therefore, the coupling effect of fiber, loess and water may be the reason for the different degrees of response of reinforced loess with different fiber content to freeze-thaw cycles. There are differences in the properties of 
lignin fiber and loess materials. After the addition of lignin fiber to the loess, the hydrophilic groups in the lignin fiber will adsorb the water in the loess. The lubrication formed by the accumulation of water in loess on the surface of fiber and detritus will weaken the strengthening effect of fiber on loess [44]. Since the adsorption capacity of fiber to water is limited, the weakening effect is limited and is not obvious when the fiber content is small. The effect of the increase of fiber content on the strength of loess is mainly enhanced. When the fiber content reaches a certain content, the weakening effect begins to be highlighted, so that the strengthening effect of fiber on loess strength begins to weaken. However, since the water in the sample is a certain content, when the fiber content in the loess exceeds a certain limit, the balanced relationship between the adsorption force of the fiber to water and the matric suction of the loess begins to change. Because of this change, the amount of water absorbed by a single fiber begins to decrease, the weakening effect begins to weaken, and the strengthening effect of the fiber on the strength of loess begins to strengthen again. This is the reason the strengthening effect of lignin fiber on loess strength is weakened when the fiber content increases from $1 \%$ to $2 \%$. This weakening effect is further magnified under freeze-thaw cycles and even leads to a negative increase in the strength of loess when the fiber content increases from $1 \%$ to $1.5 \%$.

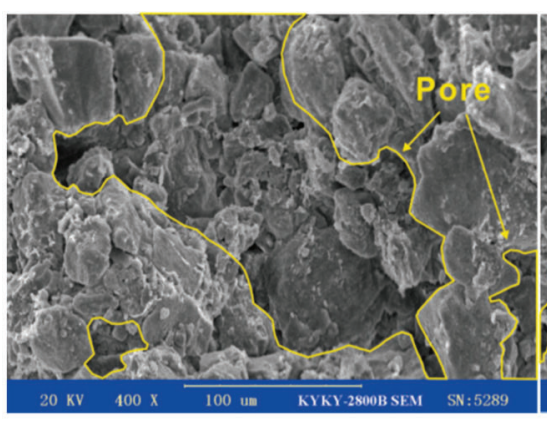

(a)

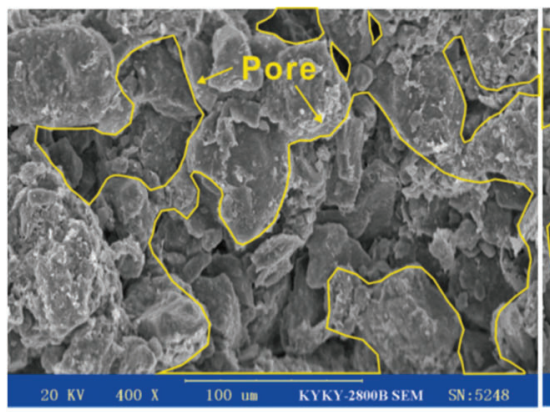

(d)

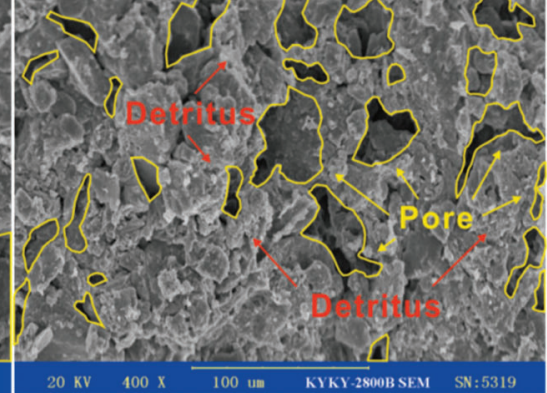

(b)

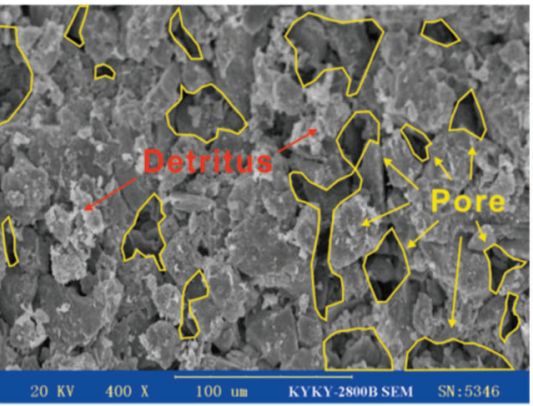

(e)

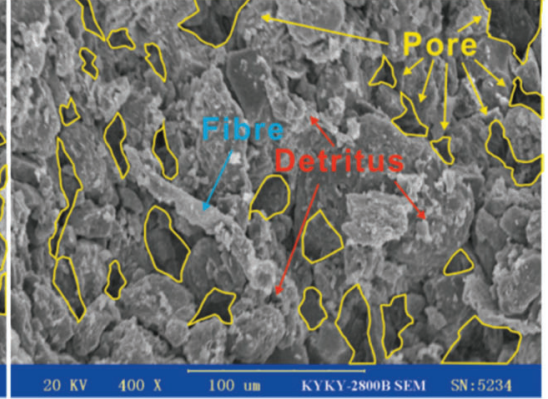

(c)

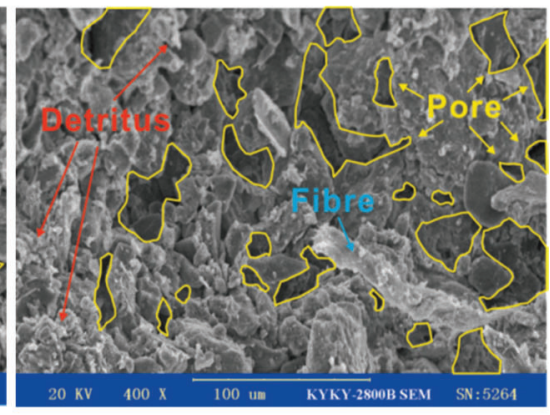

(f)

Figure 12: Microstructure of lignin fiber-reinforced loess: (a) $\mathrm{m}=0 \%, 0$ cycles; (b) $\mathrm{m}=1 \%$, 0 cycles; (c) $\mathrm{m}=3 \%, 0$ cycles; (d) $\mathrm{m}=0 \%, 10$ cycles; (e) $\mathrm{m}=1 \%, 10$ cycles; (f) $\mathrm{m}=3 \%, 10$ cycles

As shown in Fig. 13, the relationship between fiber content and this amplification effect can be explained by comparing the strengthening effect of Fiber per unit content in specimens with different fiber content without and after freeze-thaw cycles. The strengthening effect of per unit fiber content is the UCS value corresponding to $1 \%$ fiber in reinforced loess with different fiber content. 


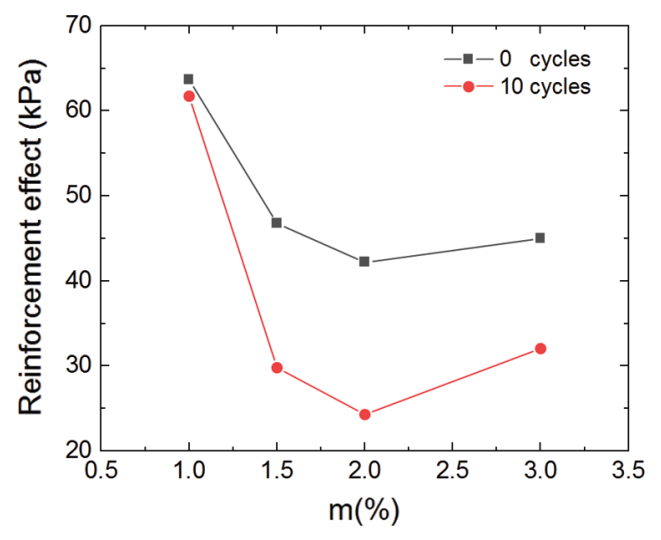

Figure 13: Unit fiber reinforcement effect

\section{Conclusions}

In this paper, the effects of freeze-thaw cycles and fiber content on lignin fiber-reinforced loess have been discussed, and the following conclusions can be drawn:

(1) Lignin fiber can reduce the softening degree of frozen-thawed loess under unconfined conditions, and strengthen the UCS of loess. Without freeze-thaw cycles, the strengthening effect of lignin fiber on loess increases with the increase in fiber content, but the growth rate is different. After 5 freeze-thaw cycles, the strengthening effect of lignin fiber on loess increases at first and then decreases, and then enhances again with the increase in fiber content. Under different freezethaw cycles, the enhancement rate of UCS of lignin fiber-reinforced loess is the fastest when the fiber content increases from $0 \%$ to $1 \%$.

(2) Under the condition of freeze-thaw cycles, the stable cycle times and UCS loss rate of reinforced loess with different fiber content are different. The stable cycle times and strength loss rate of high fiber content reinforced loess are significantly higher than those of low fiber content reinforced loess. Under the condition of freeze-thaw cycles, the reinforced loess with $1 \%$ fiber content enters the stable state fastest, the strength loss rate is the smallest, and the stability is the best.

(3) Under the condition of freeze-thaw cycles, the deformation modulus of reinforced loess will decrease with the increase of fiber content, until the fiber content increases to a certain extent (over 1.5\%). The effect of freeze-thaw cycles on the deformation modulus of reinforced loess with different fiber content is different. The deformation modulus of reinforced loess with $0 \%$ and $1 \%$ fiber content increase under freeze-thaw cycles, and its ability to resist deformation becomes stronger.

(4) When the fiber content stay in a certain range, the strengthening effect of lignin fiber on loess will be weakened due to the coupling effect of fiber, loess and water. The freeze-thaw effect will further amplify this weakening effect, and when the fiber content increases to a certain extent (1\%), the strengthening effect on loess begins to weaken. Excessive fiber content is not conducive to the improvement of loess strength, and the best fiber content of lignin fiber-reinforced loess under freeze-thaw cycles is $1 \%$.

Acknowledgement: Authors are grateful for the support provided by Master Liu Fuqiang who participated in the test.

Funding Statement: This study was supported in part by the Earthquake Science and Technology Development Fund, Gansu Earthquake Agency (Grant Nos. 2021M7, 2019Q08), the Construction Project 
of Scientific Research team of Seismological Bureau of Gansu Province (Grant No. 2020TD-01-01), the National Natural Science Foundation of China (Grant No. 51778590).

Conflicts of Interest: The authors declare that they have no conflicts of interest to report regarding the present study.

\section{References}

1. Pécsi, M. (1990). Loess is not just the accumulation of dust. Quaternary International, 7-8, 1-21. DOI 10.1016/ 1040-6182(90)90034-2.

2. Li, Y. R., Shi, W. H., Aydin, A., Beroya-Eitner, M. A., Gao, G. H. (2019). Loess genesis and worldwide distribution. Earth-Science Reviews, 201, 102947. DOI 10.1016/j.earscirev.2019.102947.

3. Grabowska-Olszewska, B. (1975). SEM analysis of microstructures of loess deposits. Bulletin of Engineering Geology and the Environment, 11(1), 45-48. DOI 10.1007/BF02635451.

4. Jefferson, I., Rogers, C., Evstatiev, D., Karastanev, D. (2005). Chapter 25 treatment of metastable loess soils: Lessons from Eastern Europe. Elsevier Geo-Engineering Book Series, 3(5), 723-762. DOI 10.1016/S15719960(05)80028-X.

5. Jiang, M. J., Li, T., Hu, H. J., Thornton, C. (2014). DEM analyses of one-dimensional compression and collapse behaviour of unsaturated structural loess. Computers and Geotechnics, 60, 47-60. DOI 10.1016/j. compgeo.2014.04.002.

6. Wang, L. M., Shi, Y. C., Liu, X. (2003). Loess dynamics. Seismological Press, China.

7. Derbyshire, E. (2001). Geological hazards in loess terrain, with particular reference to the loess regions of China. Earth Science Reviews, 54(1-3), 231-260. DOI 10.1016/S0012-8252(01)00050-2.

8. Li, P. Y., Qian, H. (2018). Water in loess. In: Meyers R. A. (ed.), Encyclopedia of sustainability science and technology. Springer, New York.

9. Li, G. Y., Ma, W., Mu, Y. H., Wang, F. (2017). Effects of freeze-thaw cycle on engineering properties of loess used as road fills in seasonally frozen ground regions, North China. Journal of Mountain Science, 14(2), 356-368. DOI 10.1007/s11629-016-4005-4.

10. Evstatiev, D. (1988). Loess improvement methods. Engineering Geology, 25(2-4), 341-366. DOI 10.1016/00137952(88)90036-1.

11. Li, G. Y., Wang, F., Ma, W., Fortier, R., Mu, Y. H. et al. (2018). Variations in strength and deformation of compacted loess exposed to wetting-drying and freeze-thaw cycles. Cold Regions Science and Technology, 151, 159-167. DOI 10.1016/j.coldregions.2018.03.021.

12. Zhou, Z. W., Ma, W., Zhang, S. J., Mu, Y. H., Li, G. Y. (2018). Effect of freeze-thaw cycles in mechanical behaviors of frozen loess. Cold Regions Science and Technology, 146, 9-18. DOI 10.1016/j.coldregions.2017.11.011.

13. Gao, C. H., Du, G. Y., Guo, Q., Zhuang, Z. X. (2020). Static and dynamic behaviors of basalt fiber-reinforced cement-soil after freeze-thaw cycle. KSCE Journal of Civil Engineering, 24(12), 3573-3583. DOI 10.1007/ s12205-020-2266-5.

14. Zhang, W. Y., Guo, A. B., Lin, C. (2019). Effects of cyclic freeze and thaw on engineering properties of compacted loess and lime-stabilized loess. Journal of Materials in Civil Engineering, 31(9), 04019205. DOI 10.1061/(ASCE) MT.1943-5533.0002858.

15. Zhang, Y., Johnson, A. E., White, D. J. (2019). Freeze-thaw performance of cement and fly ash stabilized loess. Transportation Geotechnics, 21(8), 100279. DOI 10.1016/j.trgeo.2019.100279.

16. Zaimoglu, A. S. (2010). Freezing-thawing behavior of fine-grained soils reinforced with polypropylene fibers. Cold Regions Science and Technology, 60(1), 63-65. DOI 10.1016/j.coldregions.2009.07.001.

17. Kravchenko, E., Liu, J. K., Niu, W. W., Zhang, S. J. (2018). Performance of clay soil reinforced with fibers subjected to freeze-thaw cycles. Cold Regions Science and Technology, 153, 18-24. DOI 10.1016/j.coldregions.2018.05.002.

18. Orakoglu, M. E., Liu, J. K. (2017). Effect of freeze-thaw cycles on triaxial strength properties of fiber-reinforced clayey soil. KSCE Journal of Civil Engineering, 21(6), 2128-2140. DOI 10.1007/s12205-017-0960-8. 
19. Yarbai, N. (2020). Effect of freezing-thawing on clayey soils reinforced with human hair fibers. Journal of Natural Fibers, 17(6), 921-931. DOI 10.1080/15440478.2019.1690614.

20. Liu, C., Lv, Y. R., Yu, X. J., Wu, X. (2020). Effects of freeze-thaw cycles on the unconfined compressive strength of straw fiber-reinforced soil. Geotextiles and Geomembranes, 48(4), 581-590. DOI 10.1016/j.geotexmem.2020.03.004.

21. Li, Y., Ling, X. Z., Lei, S., An, L. S. (2018). Tensile strength of fiber-reinforced soil under freeze-thaw condition. Cold Regions Science and Technology, 146, 53-59. DOI 10.1016/j.coldregions.2017.11.010.

22. Güllü, H., Khudi, A. S. (2014). Effect of freeze-thaw cycles on unconfined compressive strength of fine-grained soil treated with jute fiber, steel fiber and lime. Cold Regions Science and Technology, 106, 55-65. DOI 10.1016/j. coldregions.2014.06.008.

23. Eskisa, T., Altun, S. (2016). Strength development and post freeze-thaw behavior of kaolin reinforced with fibers. Japanese Geotechnical Society Special Publication, 2(64), 2159-2163. DOI 10.3208/jgssp.OTH-14.

24. Zaimoglu, A. S., Yetimoglu, T. (2012). Strength behavior of fine grained soil reinforced with randomly distributed polypropylene fibers. Geotechnical and Geological Engineering, 30(1), 197-203. DOI 10.1007/s10706-0119462-5.

25. Tran, K. Q., Satomi, T., Takahashi, H. (2019). Tensile behaviors of natural fiber and cement reinforced soil subjected to direct tensile test. Journal of Building Engineering, 24, 100748. DOI 10.1016/j.jobe.2019.100748.

26. Higgins, D. (2007). Briefing: GGBS and sustainability. Construction Materials, 160(3), 99-101. DOI 10.1680/ coma.2007.160.3.99.

27. Chen, R. P., Drnevich, V. P., Daita, R. K. (2009). Short-term electrical conductivity and strength development of lime kiln dust modified soils. Journal of Geotechnical and Geoenvironmental Engineering, 135(4), 590-594. DOI 10.1061/(ASCE)1090-0241(2009)135:4(590).

28. Tang, C. S., Shi, B., Gao, W., Chen, F. J., Cai, Y. (2007). Strength and mechanical behavior of short polypropylene fiber-reinforced and cement stabilized clayey soil. Geotextiles and Geomembranes, 25(3), 194-202. DOI 10.1016/ j.geotexmem.2006.11.002.

29. Day, R. W., Rollings, R. S., Burkes, J. P., Rollings, M. P. (2000). Sulfate attack on cement-stabilized sand. Journal of Geotechnical and Geoenvironmental Engineering, 126(10), 944-946. DOI 10.1061/(asce)1090-0241(2000) 126:10(944).

30. Jiang, T. D. (2008). Lignin. Chemical Industry Press, China.

31. Alazigha, D. P., Indraratna, B., Vinod, J. S., Heitor, A. (2018). Mechanisms of stabilization of expansive soil with lignosulfonate admixture. Transportation Geotechnics, 14, 81-92. DOI 10.1016/j.trgeo.2017.11.001.

32. Zhang, T., Cai, G. J., Liu, S. Y. (2017). Assessment of mechanical properties in recycled lignin-stabilized silty soil as base fill material. Journal of Cleaner Production, 172, 1788-1799. DOI 10.1016/j.jclepro.2017.12.011.

33. Zhang, T., Cai, G. J., Liu, S. Y. (2018). Application of lignin-stabilized silty soil in highway subgrade: A macroscale laboratory study. Journal of Materials in Civil Engineering, 30(4), 04018034. DOI 10.1061/ (ASCE)MT.1943-5533.0002203.

34. Kong, X. H., Song, S. G., Wang, M. Y., Zhao, Q. M. (2019). Experimental research of low liquid limit silt stabilized by lignin in the flooding area of Yellow River. Geotechnical and Geological Engineering, 37(6), 5211-5217. DOI 10.1007/s10706-019-00975-1.

35. Wang, Q., Zhong, X. M., Ma, H. P., Wang, S. Y., Liu, Z. Z. et al. (2020). Microstructure and reinforcement mechanism of lignin-modified loess. Journal of Materials in Civil Engineering, 32(11), 04020319. DOI 10.1061/(ASCE)MT.1943-5533.0003422.

36. Liu, Y. W., Chang, M. S., Wang, Q., Wang, Y. F., Liu, J. Y. (2020). Use of sulfur-free lignin as a novel soil additive: A multi-scale experimental investigation. Engineering Geology, 269, 105551. DOI 10.1016/j.enggeo.2020.105551.

37. Ministry of Housing and Urban-Rural Development of the People's Republic of China (2019). Specification of Soil Test: GB/T50123-2019. China Architecture and Building Press, China.

38. Ministry of Transport of the People's Republic of China (2015). Specifications for Design of Highway Subgrades: JTG D30-2015. China Communications Press, China. 
39. Wang, Q., Wang, L. M., Zhong, X. M., Guo, P., Wang, J. et al. (2021). Dynamic behaviour and constitutive relationship of saturated fly ash-modified loess. European Journal of Environmental and Civil Engineering, 25(7), 1302-1317. DOI 10.1080/19648189.2019.1577181.

40. Wang, Q., Liu, Z. Z., Zhong, X. M., Gao, Z. N., Liu, F. Q. (2021). Dynamic elastic modulus and damping ratio of lignin-modified loess. Journal of Renewable Materials, 9(3), 523-540. DOI 10.32604/jrm.2021.014114.

41. Lu, J., Wang, T. H., Cheng, W. C., Yang, T., Luo, Y. (2019). Permeability anisotropy of loess under the influence of dry density and freeze-thaw cycles. International Journal of Geomechanics, 19(9), 04019103. DOI 10.1061/ (ASCE)GM.1943-5622.0001485.

42. Liu, X. J., Fan, J. Y., Yu, J., Gao, X. (2021). Solidification of loess using microbial induced carbonate precipitation. Journal of Mountain Science, 18(1), 265-274. DOI 10.1007/s11629-020-6154-8.

43. Dove, J. E., Frost, J. D. (1999). Peak friction behavior of smooth geomembrane-particle interfaces. Journal of Geotechnical and Geoenvironmental Engineering, 125(7), 544-555. DOI 10.1061/(ASCE)1090-0241(1999) 125:7(544).

44. Wang, Y. X., Guo, P. P., Shan, S. B., Yuan, H. P., Yuan, B. X. (2016). Study on strength influence mechanism of fiber-reinforced expansive soil using jute. Geotechnical and Geological Engineering, 34(4), 1079-1088. DOI 10.1007/s10706-016-0028-4. 